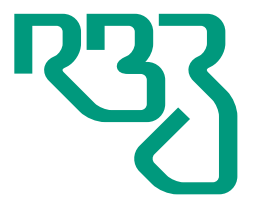

\section{Revista}

Brasileira de

Zootecnia

Brazilian Journal of Animal Science

ISSN 1806-9290

www.rbz.org.br

\title{
Does high stereotypic behavior expression affect productivity measures in sows?
}

\author{
Patricia Tatemoto $^{1}$ (iD, Thiago Bernardino ${ }^{1}$ iD, Frederico Augusto \\ Mazzocca Lopes Rodrigues ${ }^{1}$, Adroaldo José Zanella ${ }^{1^{*}}$ iD \\ ${ }^{1}$ Universidade de São Paulo, Faculdade de Medicina Veterinária e Zootecnia, Departamento \\ de Medicina Veterinária Preventiva e Saúde Animal, Pirassununga, SP, Brasil.
}

\author{
*Corresponding author: \\ adroaldo.zanella@usp.br \\ Received: July 3, 2018 \\ Accepted: February 27, 2019 \\ How to cite: Tatemoto, P.; Bernardino, T.; \\ Rodrigues, F. A. M. L. and Zanella, A. J. 2019. \\ Does high stereotypic behavior expression \\ affect productivity measures in sows? Revista \\ Brasileira de Zootecnia 48:e20180135. \\ https://doi.org/10.1590/rbz4820180135 \\ Copyright: This is an open access article \\ distributed under the terms of the \\ Creative Commons Attribution License \\ (http://creativecommons.org/licenses/by/4.0/), \\ which permits unrestricted use, distribution, \\ and reproduction in any medium, provided the \\ original work is properly cited.
}

\begin{abstract}
The objective of this study was to evaluate the effects of stereotypic behavior on productivity measures in sows. Frequent expression of stereotypies by pigs has been reported, even when pigs are not maintained in crates. This behavior is only observed in animals kept in captivity and is a wide-range welfare indicator, since it is considered to develop in situations of chronic stress or frustration. When comparing groups of sows showing low or high frequency of stereotypy expression, we found that stereotypic behavior did not affect productivity. Moreover, it did not affect physiological welfare indicators, such as salivary cortisol concentration or glucocorticoids in the placenta. There were no differences in productivity parameters, including weight of sows, weight of piglets, number of piglets weaned, or piglet mortality. Our study was conducted in group-housing pens, where the sows were not confined. Even in this condition, which is considered for increasing welfare, the barren environment did not meet the behavioral and sensory needs of sows, which were naturally selected to perform complex behavioral repertoire and to spend part of their time engaging in exploratory behavior.
\end{abstract}

Keywords: glucocorticoids, pigs, placenta, stereotypies, welfare

\section{Introduction}

It has been reported that sows express stereotypic behavior (or stereotypies) when housed in pig production systems. This behavior arises in situations of chronic stress or frustration but can also result from a past situation or an existing conflict (Dantzer, 1991; Mason, 1991; Lawrence and Terlouw, 1993). Expression of stereotypies is considered a welfare indicator (Dantzer, 1991; Mason, 1991; Zhang et al., 2017), since the performance of such behavior reveals information about psychological state. This behavior is often observed in farm animals kept in intensive production systems, since their environments cannot meet all their needs. Factors such as recurrent and long-lasting environmental constraints (Zhang et al., 2017), as well as genetic predisposition (Schoenecker and Heller, 2000; Schwaibold and Pillay, 2001), may constitute a cumulative cascade of predisposing factors in stereotypic behavior. In some cases, stereotypies are in agreement with other indicators of reduced welfare, including changes in physiological indicators (Zhang et al., 2017).

Stereotypic behavior has been used as an animal welfare indicator in protocols used to assess farm animals [e.g., Welfare Quality ${ }^{\circledR}$ and Animal Welfare Indicators (AWIN) protocols]. However, few studies address the effects of stereotypies on productivity outcomes. Such investigations could improve the understanding of the consequences of this behavior and provide an argument for improving animal environments, thus reducing stereotypies (Borell and Hurnik, 1990; Williams and Randle, 2017). 
Cortisol concentration has been widely used as a physiological indicator of animal welfare, since chronically elevated levels of this hormone can negatively affect animals (Koolhaas et al., 2011). Glucocorticoid can be measured in the placenta, possibly causing alterations in brain development of the offspring. One possible cause is the cortisol concentration in the mother and the activity of 11ß-hydroxysteroid dehydrogenase enzyme in the placenta (Seckl, 2004; Abe et al., 2007; Nolvi et al., 2016).

The question is, how does stereotypic behavior affect animal welfare and productivity? It is important that factors that scientists consider key to welfare of farm animals coincide with improvements in productivity, making it easier to convince producers to rethink their practices. If scientists fail to demonstrate that improvements which enhance animal welfare result in economic gains, the changes will only occur as a result of moral values and ethical requirements. Our objective was to evaluate the physiological welfare indicators and productivity implications of stereotypy expression by sows.

\section{Material and Methods}

This study was approved by the local Ethics Committee on Animal Use (CEUA; protocol number 3606300114). The study was conducted in an experimental pig farm in Pirassununga, Brazil.

A total of 28 pregnant sows from a group of 36 animals were used for this study (eight sows returned to estrus). The animals were TopGen Afrodite ${ }^{\circledR}$ sows of nulliparous lineage (Jaguariaíva, Paraná, Brazil). A parallel experiment involving the same animals evaluated the effect of dietary fiber. The animals were distributed by weight into two treatments (diets with high or low fiber). The sows were inseminated with pooled semen. The insemination protocol comprised three inseminations: one at the time of estrus identification, the second $24 \mathrm{~h}$ after the first insemination, and the third $36 \mathrm{~h}$ after the first insemination. The average age of animals at the first insemination was $291 \pm 21$ days.

Sows in both groups were kept in a group-housing system during pregnancy, with nine animals per pen, individual feeders, and water ad libitum. Immediately prior to feeding, there was a sound stimulus to reduce the anticipatory responses related to feed and to the presence of humans. Animals were confined in individual crates during feeding. Sows had no access to water for 20 min during feeding because of a shared feed-water connection that could have mixed water with the feed. Thirty minutes after the start of feeding, all the animals were released.

The pen was $6.7 \mathrm{~m}$ wide $\times 4.4 \mathrm{~m}$ long, totaling $29.48 \mathrm{~m}^{2}\left(3.27 \mathrm{~m}^{2}\right.$ per animal), excluding the area of feeders. Each pen had nine individual gestation crates measuring $1.80 \times 0.55 \mathrm{~m}$ each, with masonry feeders and nipple drinkers for ad libitum access. The total area per animal was $4.38 \mathrm{~m}^{2}$. The floors of the pens were solid concrete, and pen was covered with 12 rubber mats measuring $100 \mathrm{~cm}^{2}$ and $30 \mathrm{~mm}$ high (EBV 30-Vedovati ${ }^{\circledR}$ ). The pens were divided by a straight line consisting of seven non-electrified wires, with an access gate for each pen. Pens were cleaned each morning.

The mean temperature during gestation was $21.1{ }^{\circ} \mathrm{C}$ (maximum: $38.9{ }^{\circ} \mathrm{C}$, minimum: $8.4{ }^{\circ} \mathrm{C}$ ), and the mean humidity was 61.91\%; rainfall during this period totaled $534.6 \mathrm{~mm}$ (March 26 through October 31,2015 ). The average temperature during the lactation period was $22.7^{\circ} \mathrm{C}$ (maximum: $38.9^{\circ} \mathrm{C}$, minimum: $8.5^{\circ} \mathrm{C}$ ). The mean humidity during the lactation period was $61.15 \%$, and rainfall totaled $522.6 \mathrm{~mm}$ (August 1 through November 30, 2015). Meteorological data were obtained from the Fernando Costa Campus station, which is located approximately $1100 \mathrm{~m}$ from the pig farm.

To assess the stereotypic behavior (sham-chewing) of individual sows, behavioral observations were conducted throughout the pregnancy. There were gradients in expression of stereotypies by sows. To understand our data, we divided the sows into two groups: low and high level of stereotypic behavior (sham-chewing - Figure 1). Sows $(N=28)$ were ranked by high and low rates of stereotypic behavior ( $\mathrm{N}=14$ in each group); welfare indicators such as sow behavior, hypothalamic-pituitary-adrenal axis activity, and feeding motivation were analyzed. Moreover, production parameters were evaluated, including weight of sows at the end of gestation and during 
lactation period, piglet mortality, and piglet weight. Placenta glucocorticoid (cortisol and cortisone) levels were assessed, because this indicator can provide information on piglet development and possible fetal exposure to glucocorticoids.

An ethogram was adapted (Table 1; it included different behaviors; Zonderland et al., 2004) for collection of behavioral data. Behavioral measures of sows were obtained by direct observation on days 29, 30, $31,59,60,61,74,75,76,89,90$, and 91 for each group. Behavioral assessments were performed by direct observation $1 \mathrm{~h}$ before and $1 \mathrm{~h}$ after the two feeding times, totaling four moments of observation by day. Five observers were previously trained to standardize the methodology and avoid bias in data collection. Observations were carried out using a combination of methods for behavioral measures; the process started with a scan sample, followed by continuous observation of a focal animal. At each observation episode, each animal was observed uninterruptedly three times for $120 \mathrm{~s}$ at each period, totaling 6 min per animal per observation episode (before and after feeding), with a total of $24 \mathrm{~min}$ of observation per day. The observations were conducted over three consecutive days to avoid possible interference by stressful events (e.g., days 29, 30, and 31 during the first third of pregnancy, following the same observation protocol on three consecutive days).

Table 1 - Definition of behaviors for behavioral observation of pregnant gilts

\begin{tabular}{ll}
\hline Behavior & Animal sleeping \\
Sleep & Lying with the belly facing the ground with all the limbs under the body \\
Lying ventrally & Lying sideways, with all the members extended laterally \\
Lying laterally & Body supported by the four limbs \\
Standing & Continuous chewing without the presence of visible food in the oral cavity \\
Sham-chewing & Snout touches the ground followed by head movements \\
Rooting the floor & Tongue touches the floor and is followed by movements with the head \\
Licking the floor & Biting or nibbling the fence wire or gate \\
Interacting fence or gate & Snout or tongue touches mats followed by head movements \\
Interacting with mats & Bite on any parts of the body (tail, vulva, ear, body) \\
Bites (E) & Face to face, with fixed view to the other animal \\
Facing (E) & Pushing another animal using the head or the muzzle \\
Pushing (E) & Sound emitted by the animal \\
Vocalization (E) & The sum of sleep, lying ventrally, and lying laterally \\
Rest & The sum of sham chewing, rooting the floor, licking the floor, interacting with fence or gate, \\
and interacting with mats
\end{tabular}

"E" indicates measured behaviors - only the events and not the duration [adapted from Zonderland et al. (2004)].

A

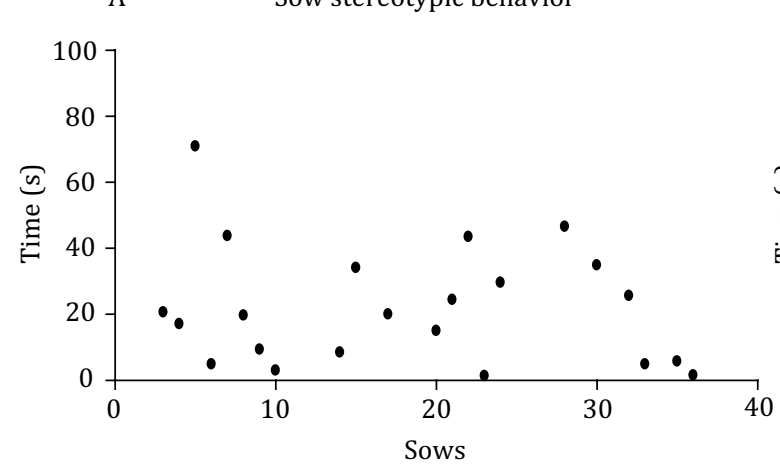

B

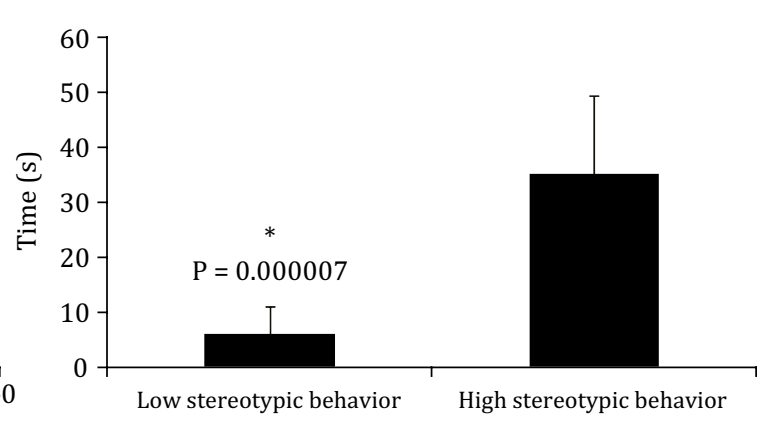

Figure 1 - Sow stereotypic behavior distribution. 
A feed motivation test was performed (based on Souza da Silva et al., 2013) in the final third of gestation. Initially, $2 \mathrm{~kg}$ of feed was provided for each animal, and small extra portions were supplied gradually when almost all feed had been consumed, with a limit of another $2 \mathrm{~kg}$ of feed. Therefore, the total amount of each test consisted of $4 \mathrm{~kg}$ of feed for each animal. However, to avoid the effect of palatability or volume, all animals, irrespective of treatment group, received $2 \mathrm{~kg}$ of mixed conventional and high-fiber feed. The test location was the usual feeding area, and feeding lasted $45 \mathrm{~min}$. The final weight of the second portion was measured to obtain the total weight of feed consumed. Because of the shared feed-water connection, access to water during the test was prohibited, so that accurate feed measurements could be obtained.

Saliva collection was performed on the same days of the behavioral evaluation - that is, in the first third (days 29, 30, 31), middle third (days 59, 60, 61), and last third of gestation (days 74, 75, 76, 89, 90 , and 91). These days corresponded with the average gestational age, and the three consecutive days were used to avoid possible undesirable variables to interfere with the response. Two samples were collected per animal on each of these days: the first between 6.00 and $6.30 \mathrm{~h}$, and the second between 18.00 and $18.30 \mathrm{~h}$; this timing followed the circadian rhythm of cortisol (based on Siegford et al., 2008). Samples were collected using two roller-shaped units of hydrophilic cotton (Apolo ${ }^{\circledR}$ ) tied to a dental floss (DentalClean ${ }^{\circledR}$ ) and presented to each animal. The animal chewed the cotton until it was saturated with saliva. The first sample collected was discarded; we repeated the protocol to collect only recently produced saliva. After the second sample was collected, it was introduced into a 15-mL falcon tube $\left(\mathrm{Kasvi}^{\circledR}\right)$. Subsequently, the tube was stored in a cooler until the end of the collection, sent to the laboratory, and then frozen at $-20^{\circ} \mathrm{C}$ until processing. Thawing took place in a container filled with ice in a temperature-controlled room. After complete thawing, the sample was centrifuged for $10 \mathrm{~min}$ at a rate of $1,000 \times \mathrm{g}$ (Celm Combate ${ }^{\circledR}$ ), and then the supernatant was aliquoted into microtubes $\left(\mathrm{Kasvi}^{\circledast}\right)$ and again frozen at $-20^{\circ} \mathrm{C}$ until analysis. This process assisted in the removal of mucins and other components that could interfere with the analysis protocol. A 50- $\mu \mathrm{L}$ sample was analyzed by enzyme immunoassay in duplicate for each sow, pooling each gestation period and without mixing the morning and afternoon collections (e.g., samples from 29, 30, and 31 gestation days in the morning collection). For sample analysis, $50 \mu \mathrm{L}$ of saliva was analyzed with a cortisol enzyme immunoassay (EIA - based on Cooper et al., 1989; Palme and Möstl, 1997) in duplicate for each sow, with a pool of each gestation period, without mixing the morning and afternoon collections (e.g., with samples from 88 and 89 gestation days in the morning collection). The sensitivity of the EIA was $0.2 \mathrm{pg} /$ well.

Gilts were moved to the farrowing pens at, on average, 107 days of gestation. Farrowing occurred in individual pens measuring $4.3 \times 2.0 \mathrm{~m}$ each, which contained material for building nests (hay and sugarcane bagasse) and iron bars to optimize protection of piglets from crushing. The creeps $(0.9 \times 2.2 \mathrm{~m}$ each $)$ were made of concrete; pigs kept in the creeps had access to solid feed from birth. Creep floors were lined with sugarcane bagasse, and heat was supplied with 100-W incandescent bulbs. Deliveries were monitored by video cameras with internet access (allowing observers to monitor the beginning of each delivery), followed by direct observation. Interventions were performed only when needed, following a pre-established protocol enabling standardized management measures. Assistance consisted of palpation when the interval exceeded $1 \mathrm{~h}$ and administration of injectable synthetic oxytocin ( $2 \mathrm{~mL}$ Placentex ${ }^{\circledR}$ subcutaneously) when absence of observed contractions exceeded $1 \mathrm{~h}$. Piglets had their teeth ground and ears notched under local anesthesia to minimize pain. Iron application, ear notching, and individual weighing were performed when piglets were two days old.

The placentas were collected from four piglets per sow, and four random pieces of each placenta were cut and frozen at $-20{ }^{\circ} \mathrm{C}$. All placentas from each sow were macerated together to prepare a pool representing the sow. Since the placenta was powdered, $0.1 \mathrm{~g}$ was placed into a $1.5-\mathrm{mL}$ microtube; $200 \mu \mathrm{L}$ of ultrapure water was then placed into the tube, and the mixture was homogenized in a vortex for $15 \mathrm{~s}$. After vortexing, $20 \mu \mathrm{L}$ was placed into another similar tube for total protein analysis; $1 \mathrm{~mL}$ ethyl acetate was placed into this tube with the water and placenta, vortexed for $15 \mathrm{~s}$, and centrifuged 
for $15 \mathrm{~min}$ at $4{ }^{\circ} \mathrm{C}$. Following centrifugation, $400 \mu \mathrm{L}$ of supernatant was placed into a new $1.5-\mathrm{mL}$ microtube, and a second (duplicate) sample was placed into another tube. All samples were dried overnight in a hood until all volume disappeared. To analyze glucocorticoid levels, all samples were re-suspended with the same volume using assay buffer. The analyses were performed with the same enzyme immunoassay protocol for saliva cortisol.

Residual normality of data was determined by Shapiro-Wilk test. Statistical tests are specified in the respective figures and significance was set at $\mathrm{P}<0.05$. Data that did not show normality was tested with a corresponding nonparametric statistical test. Mann-Whitney U test was used to analyze sow stereotypic behavior, saliva cortisol, piglet weight, and piglet mortality. Tukey's test was used for post-hoc analysis of piglet weight. The $t$ test was used to assess feeding motivation of sows and their weight. We also performed correlation tests between stereotypic behavior and saliva cortisol concentration, and between stereotypic behavior and other behaviors. The difference between treatments were assessed according to the following model:

$$
\mathrm{y}_{\mathrm{ij}}=\mu+\mathrm{T}_{\mathrm{i}}+\mathrm{a}_{\mathrm{j}}+\mathrm{e}_{\mathrm{ij}}
$$

in which $y_{i j}$ is the dependent variable, $\mu$ is the mean, $T_{i}$ is the fixed effect of treatment (low or high rate of stereotypic behavior expression), $a_{j}$ is the random effect of sow, and $e_{i j}$ is the residual error with mean 0 and variance $\sigma 2$.

\section{Results}

There were gradients in expression of stereotypies by sows. To understand our data, we divided the sows into two groups: low and high level of stereotypic behavior (sham-chewing - Figure 1). There was no difference in sow feeding between low- and high-stereotypic behavior sows (Figure 2A); hunger can
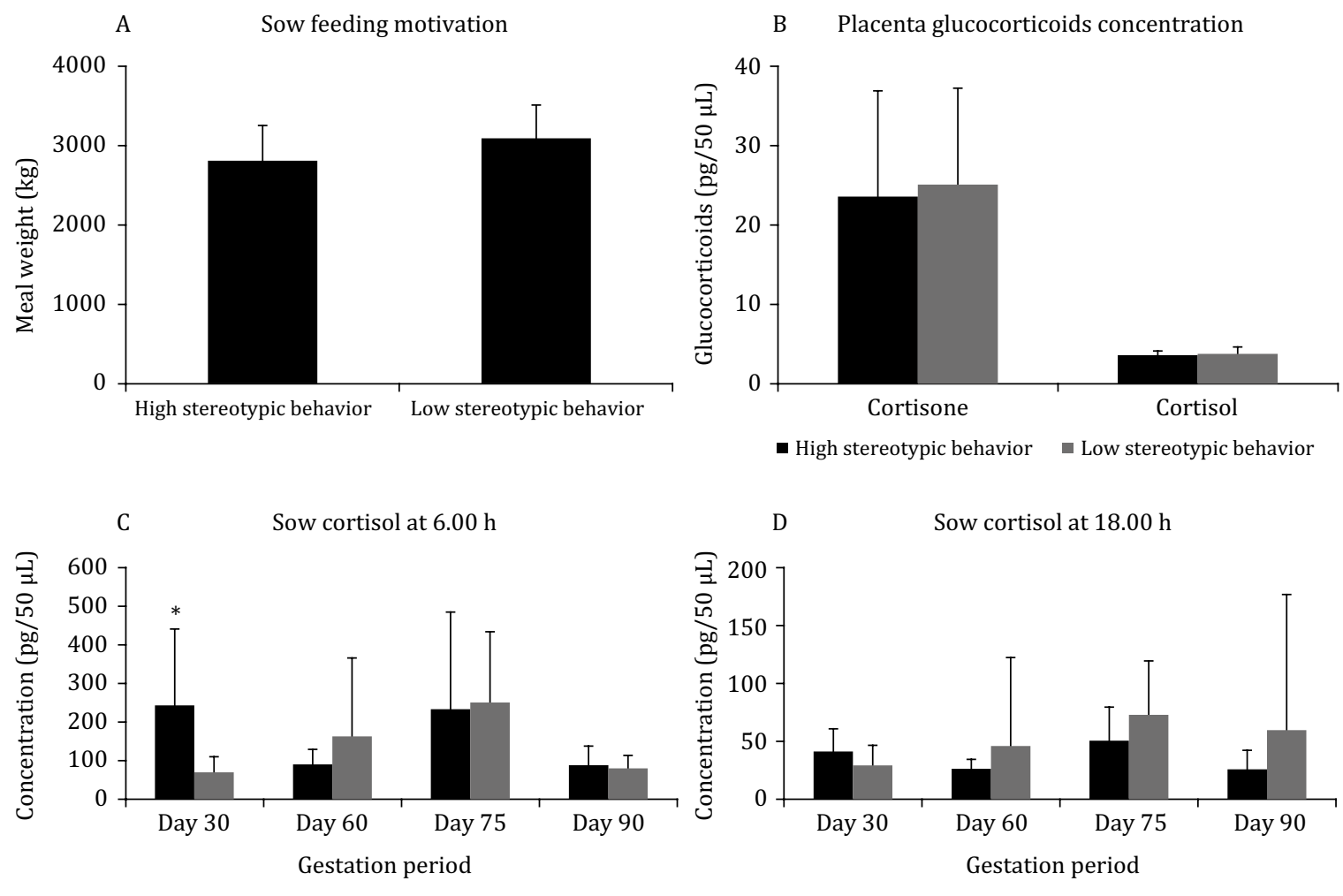

- High stereotypic behavior $\quad$ Low stereotypic behavior

- High stereotypic behavior $\quad$ Low stereotypic behavior

$\mathrm{N}=28$ (pregnant sows).

${ }^{*}$ Difference in salivary cortisol between treatments on gestation day 30 , at 6:00 h.

$t$ test: sow feeding motivation $(\mathrm{P}=0.09 ; \mathrm{F}=1.11)$; placenta cortisone $(\mathrm{P}=0.63 ; \mathrm{F}=2.43)$; placenta cortisol $(\mathrm{P}=0.55 ; 1.01)$.

Salivary cortisol data were analyzed using Mann-Whitney U test.

Figure 2 - Sow welfare indicators. 
be a main trigger of sham-chewing (Appleby and Lawrence, 1987). At the beginning of gestation, sows with high levels of stereotypical behavior had higher cortisol levels (Figure 2C); however, the difference was observed only in the morning collections. There was a significant difference in sow cortisol at $6.00 \mathrm{~h}$ on day $30(\mathrm{P}=0.01 ; \mathrm{Z}=2.38$; Figure $2 \mathrm{C})$ and a tendency at $18.00 \mathrm{~h}(\mathrm{P}=0.07 ; \mathrm{Z}=1.77$; Figure 2D). During the other gestation periods, the cortisol concentration in saliva was the same in both groups; there were no differences in the morning on day $60(\mathrm{P}=0.36 ; \mathrm{Z}=-0.89$; Figure $2 \mathrm{C})$, day $75(\mathrm{P}=0.58$; $\mathrm{Z}=-0.55$; Figure $2 \mathrm{C})$, or day $90(\mathrm{P}=0.90 ; \mathrm{Z}=-0.12$; Figure $2 \mathrm{C})$. There were no differences in the afternoon on day $60(\mathrm{P}=0.71 ; \mathrm{Z}=0.36$; Figure $2 \mathrm{D})$, day $75(\mathrm{P}=0.19 ; \mathrm{Z}=-1.28$; Figure $2 \mathrm{D})$, or day 90 $(\mathrm{P}=0.52 ; \mathrm{Z}=0.63$; Figure 2D).

There was no difference between stereotypy groups regarding placenta glucocorticoid concentration (Figure 2B).

The weights of sows were the same on day 109 of gestation (T test: $\mathrm{P}=0.90 ; \mathrm{F}=1.06$; Figure $3 \mathrm{~A}$ ) as on day 21 of lactation ( $t$ test: $P=0.32 ; F=1.75$; Figure $3 \mathrm{~A}$ ) and on day 28 of lactation ( $t$ test: $P=0.15$; $F=2.40$; Figure $3 \mathrm{~A})$. There were no differences in the number of weaned piglets $(\mathrm{t}$ test: $\mathrm{P}=0.91$; $\mathrm{F}=1.06$; Figure 3B), piglet mortality by crushing (Mann-Whitney $\mathrm{U}$ test: $\mathrm{P}=0.38 ; \mathrm{Z}=0.94$; Figure $3 \mathrm{C}$ ), or stillborn piglets (Mann-Whitney $\mathrm{U}$ test: $\mathrm{P}=0.12 ; \mathrm{Z}=1.53$; Figure $3 \mathrm{C}$ ). There was no difference in piglet weight on the first day of life (Mann-Whitney U test: $P=0.19 ; Z=-1.31$; Figure 3D), on day 21 (Mann-Whitney U test: $\mathrm{P}=0.34 ; \mathrm{Z}=-0.93$; Figure $3 \mathrm{D}$ ), or on day 28 (Mann-Whitney U test: $\mathrm{P}=0.68$; $\mathrm{Z}=-0.40$; Figure 3D).

There was no correlation between stereotypic behavior and salivary cortisol concentration (Spearman correlation: $\mathrm{P}=0.76 ; \mathrm{r}=0.021$ ) during gestation in any period. A correlation analysis was performed between stereotypic behavior duration and each behavior. There was a correlation only with inactivity

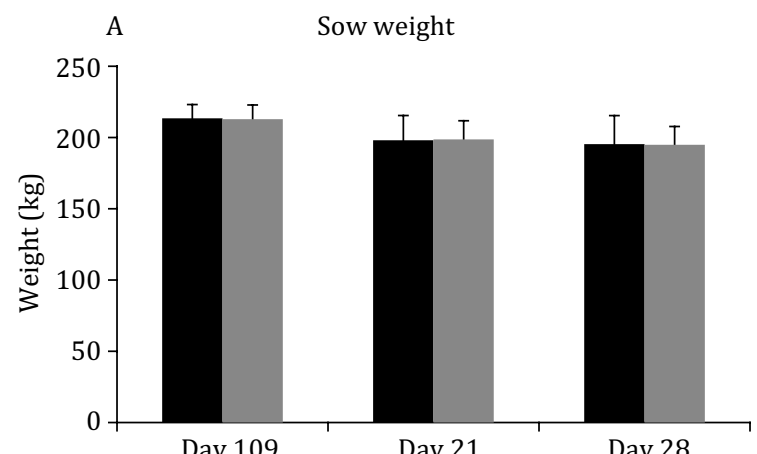

Days of gestation (Day 109) and lactation (Days 21 and 28)

- High stereotypic behavior $\quad$ Low stereotypic behavior

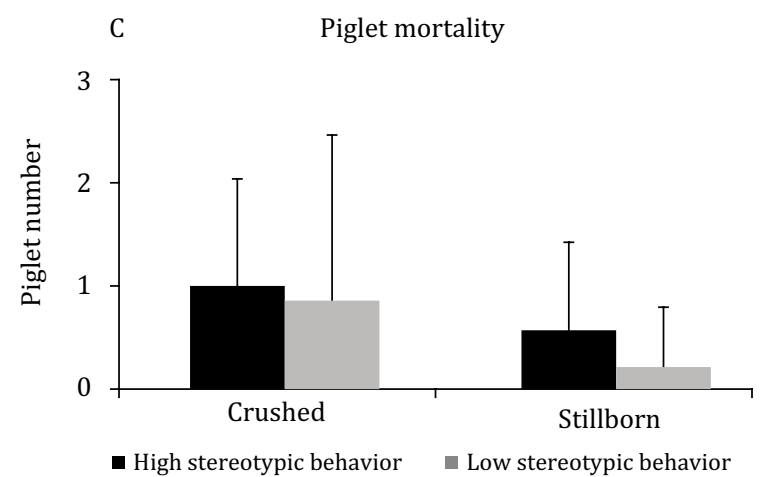

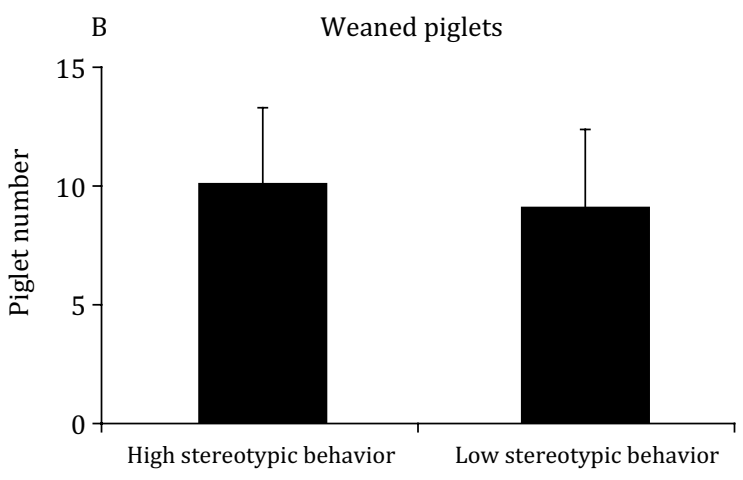

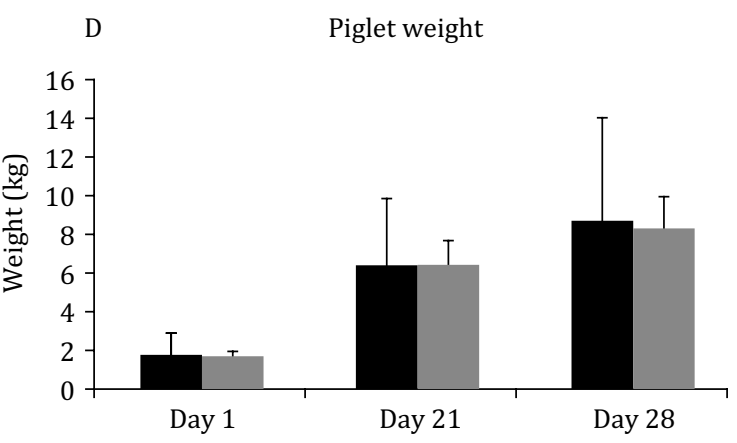

- High stereotypic behavior a Low stereotypic behavior

$\mathrm{N}=28$ (pregnant female housed in collective pens) and their respective litters.

Figure 3 - Productivity indicators. 
$\left(\mathrm{P}=0.05 ; \mathrm{R}^{2}=0.13\right)$ but not with activity $\left(\mathrm{P}=0.46 ; \mathrm{R}^{2}=0.02\right)$, foraging $\left(\mathrm{P}=0.55 ; \mathrm{R}^{2}=0.01\right)$, exploratory behaviors $\left(P=0.86 ; R^{2}=0.001\right)$, or agonistic behaviors $\left(P=0.81 ; R^{2}=0.002\right)$.

\section{Discussion}

We showed that stereotypic behavior does not affect physiological welfare indicators or productivity. However, we showed that expression of these behaviors does not affect the production outcomes we analyzed (only one delivery). Contrary to our data, there are suggestions in the livestock industry associating stereotypic behavior expression and reduced economic value of animal production (Borell and Hurnik, 1990). Stereotypic expression by sows during gestation has been associated with reproductive fertility, in which an increase in occurrence of stereotypic behavior is linked with a reduced number of piglets born (Borell and Hurnik, 1990). Despite this, few studies have evaluated this issue (Williams and Randle, 2017).

Due to the fact that the stereotypic behavior we analyzed was an oral one, we considered it could be associated with feed motivation. In this case, we would expect that sows with lower levels of satiety would express more stereotypic behaviors (Appleby and Lawrence, 1987), as frustration outcome of not reached motivation. However, we did not find any effect of stereotypic behavior on feed motivation. The feeding that sows received during pregnancy represented only 50 to $60 \%$ of their ad libitum intake capacity (Lawrence et al., 1988).

There was no difference in placenta glucocorticoids between stereotypic behavior groups. During stress responses, endocrine mechanisms are activated to enhance fitness of an individual, activating primarily the release of glucocorticoids and catecholamines (Möstl and Palme, 2002). Cortisol is a glucocorticoid hormone frequently used as an animal welfare indicator, because it is secreted by the adrenal glands as a response to adverse situations (Möstl and Palme, 2002). Cortisone was measured by the activity of $11 \beta$-hydroxysteroid dehydrogenase enzyme, which in turn converts cortisol into the biologically inactive molecule cortisone (Seckl, 2004; Jansson and Powell, 2007). The presence and activity of this enzyme have been related to maternal exposure to stressors during pregnancy (Jansson and Powell, 2007). Thus, if stereotypic behavior is an indicator of compromised welfare, we would expect to find differences in the concentrations of at least one of these glucocorticoids in the placenta (indirectly indicating the activity of the $11 \beta$-hydroxysteroid dehydrogenase enzyme). Moreover, stereotypic behavior may be associated with other physiological mechanisms, including opioids (Cronin et al., 1985; Zanella et al., 1996).

The absence of significance differences in placental glucocorticoid concentrations is consistent with salivary cortisol concentrations during gestation. On day 30 (days 29, 30, and 31) of gestation, there was a difference in salivary cortisol concentration. On that day, sows that expressed more stereotypic behavior had higher concentrations of salivary cortisol ( $\mathrm{P}=0.05)$; a tendency was observed in the afternoon samples $(\mathrm{P}=0.07)$. The concentrations did not differ between groups for the rest of gestation. A possible explanation for this result is fear, because there was intense interaction with humans in the first saliva collection. After that, the concentrations were the same due to habituation resulting from frequent contact with humans. These physiological responses in which cortisol concentrations were higher in sows expressing more stereotypic behavior may be related to individual variation (Ijichi et al., 2013; Joshi and Pillay, 2016). However, there was no correlation between stereotypic behavior and salivary cortisol concentrations throughout the pregnancy, with differences in concentrations observed only in the initial third of gestation. The possibility that stereotypic behavior reduces stress would be corroborated if the difference in concentrations persisted. However, these data were consistent with previous studies that showed that expression of stereotypic behaviors does not alter cortisol concentrations (Terlouw et al., 1991).

In terms of productivity data, there was no difference in the weight of sows at the end of gestation (day 109) or in lactation (days 21 and 28). In addition, there was no difference in the number of weaned piglets, piglet mortality, or piglet weight. Thus, we showed that the expression of stereotypic behaviors does not compromise productivity parameters in pigs. However, genetic improvement has selected 
maternal breeding with characteristics based on productivity; consequently, although conditions are not optimal, the sows exhibited high productivity indexes. Another factor that may interfere with the results is the age of animals. Some studies have shown that older sows have higher concentrations of serum cortisol, cytokines, and sham-chewing behavior (Zhang et al., 2017). However, the sows in our study were homogeneous in age, lineage, and body weight. Moreover, experiences during development were similar, such as environment in which their mothers were maintained during gestation, weaning, handling, and transport.

Scientific evidence to date does not fully elucidate what it means, in terms of animal welfare, to express stereotypies. Our questions were based on whether we consider animals equally challenged (excluding the fact that environmental challenges affect each individual differently) or whether the one that expresses stereotypic behaviors is worse than the one that does not. On the other hand, is the expression of these behaviors a way of mitigating and dealing with external stressors? Alternatively, are stereotypic behaviors merely a way of dealing with the input reduction of stimuli to the sensory system? We believe that expression of stereotypic behaviors is a strategy to deal with environmental challenges and that this expression improves welfare. In this sense, stereotypic behavior is a sign that basically tells us there is a high likelihood that welfare is compromised, because the trigger (challenges) exists. Although only some animals use this strategy, those that express stereotypic behavior fare better than those that do not express it.

There is concern that if we cannot convince producers that economic losses are related to stereotypic behavior and that changes are needed for profitable reasons, we will rely only on changes made for ethical reasons. This takes much longer, because it requires moral concern from consumers and society. Apart from this, our work was conducted in group-housed pens, where the sows are not as confined as in gestation crates. However, even though sows were housed in better conditions, the poor environment does not meet the sensory needs of these animals that have been naturally selected to perform much more complex activities and to spend part of their time in exploratory behaviors. Above all, some of these systems have sows spend the first month confined in crates that have since been abolished, and then they are regrouped with unknown sows because they are selected by body score, ultimately resulting in a high frequency of agonistic behaviors. Although pig production systems have advanced in terms of animal comfort, they still do not meet the needs of animals.

\section{Conclusions}

Stereotypic behavior does not affect physiological welfare indicators or productivity. However, genetic improvement has selected maternal breeding with characteristics based on productivity; consequently, although conditions are not optimal, sows exhibit high productivity indexes. We believe that expression of stereotypic behaviors is a strategy to deal with environmental challenges and that this expression improves welfare. In this sense, stereotypic behavior is a sign that tells us that welfare is compromised, because the trigger (challenges) exists. Although only some animals use this strategy, those that express stereotypic behavior fare better than those that do not express it. Moreover, the association between stereotypic behavior and welfare remains unclear; there is a possibility that animals that express stereotypic behaviors cope better with a low-stimulus environment than animals that do not express such behaviors.

\section{Acknowledgments}

We are grateful to the Departamento de Medicina Veterinária Preventiva e Saúde Animal (Faculdade de Medicina Veterinária e Zootecnia/Universidade de São Paulo) and Conselho Nacional de Desenvolvimento Científico e Tecnológico (CNPq), for the funds that were provided. We are also grateful to Beate von Staa, from Araporanga Farm, Jaguariaíva, for the provision of animals. The project FAPESP 2018/01082-4 contributed with resources for this research.

R. Bras. Zootec., 48:e20180135, 2019 


\section{References}

Abe, H.; Hidaka, N.; Kawagoe, C.; Odagiri, K.; Watanabe, Y.; Ikeda, T.; Ishizuka, Y.; Hashiguchi, H.; Takeda, R.; Nishimori, T. and Ishida, Y. 2007. Prenatal psychological stress causes higher emotionality, depression-like behavior, and elevated activity in the hypothalamo-pituitary-adrenal axis. Neuroscience Research 59:145-151. https://doi.org/10.1016/j.neures.2007.06.1465

Appleby, M. C. and Lawrence, A. B. 1987. Food restriction as a cause of stereotypic behaviour in tethered gilts. Animal Production 45:103-110. https://doi.org/10.1017/S0003356100036680

Borell, E. V. and Hurnik, J. F. 1990. Stereotypic behavior and productivity of sows. Canadian Journal of Animal Science 70:953-956. https://doi.org/10.4141/cjas90-114

Cooper, T. R.; Trunkfield, H. R.; Zanella, A. J. and Booth, W. D. 1989. An enzyme-linked immunosorbent assay for cortisol in the saliva of man and domestic farm animals. Journal of Endocrinology 123:R13-R16. https://doi.org/10.1677/ joe.0.123R013

Cronin, G. M.; Wiepkema, P. R. and van Ree, J. M. 1985. Endogenous opioids are invelved in abnormal stereotyped behaviours of tethered sows. Neuropeptides 6:527-530. https://doi.org/10.1016/0143-4179(85)90114-3

Dantzer, R. 1991. Stress, stereotypies and welfare. Behavioural Processes 25:95-102. https://doi.org/10.1016/03766357(91)90012-0

Ijichi, C. L.; Collins, L. M. and Elwood, R. W. 2013. Evidence for the role of personality in stereotypy predisposition. Animal Behaviour 85:1145-1151. https://doi.org/10.1016/j.anbehav.2013.03.033

Jansson, T. and Powell, T. L. 2007. Role of the placenta in fetal programming: underlying mechanisms and potential interventional approaches. Clinical Science (London, England : 1979) 113:1-13. https://doi.org/10.1042/CS20060339

Joshi, S. and Pillay, N. 2016. Association between personality and stereotypic behaviours in the African striped mouse Rhabdomys dilectus. Applied Animal Behaviour Science 174:154-161. https://doi.org/10.1016/j. applanim.2015.11.021

Koolhaas, J. M.; Bartolomucci, A.; Buwalda, B.; de Boer, S. F.; Flügge, G.; Korte, S. M.; Meerlo, P.; Murison, R.; Olivier, B.; Palanza, P.; Richter-Levin, G.; Sgoifo, A.; Steimer, T.; Stiedl, O.; van Dijk, G.; Wöhr, M. and Fuchs, E. 2011. Stress revisited: A critical evaluation of the stress concept. Neuroscience and Biobehavioral Reviews 35:1291-1301. https://doi.org/10.1016/j.neubiorev.2011.02.003

Lawrence, A. B.; Appleby, M. C. and Macleod, H. A. 1988. Measuring hunger in the pig using operant conditioning: The effect of food restriction. Animal Production 47:131-137. https://doi.org/10.1017/S0003356100037132

Lawrence, A. B. and Terlouw, E. M. C. 1993. A review of the behavioral factors involved in the development and continued performance of stereotypic behaviors in pigs. Journal of Animal Science 71:2815-2825. https://doi.org/10.2527/1993.71102815x

Mason, G. J. 1991. Stereotypies and suffering. Behavioural Processes 25:103-115.

Möstl, E. and Palme, R. 2002. Hormones as indicators of stress. Domestic Animal Endocrinology 23:67-74. https://doi.org/10.1016/S0739-7240(02)00146-7

Palme, R. and Möstl, E. 1997. Measurement of cortisol metabolites in faeces of sheep as a parameter of cortisol concentration in blood. Z. Saugetierkd. International Journal of Mammals Biology 62:192-197.

Nolvi, S.; Karlsson, L.; Bridgett, D. J.; Korja, R.; Huizink, A. C.; Kataja, E. L. and Karlsson, H. 2016. Maternal prenatal stress and infant emotional reactivity six months postpartum. Journal of Affective Disorders 199:163-170. https://doi.org/10.1016/j.jad.2016.04.020

Schoenecker, B. and Heller, K. E. 2000. Indication of a genetic basis of stereotypies in laboratory-bred bank voles (Clethrionomys glareolus). Applied Animal Behaviour Science 68:339-347. https://doi.org/10.1016/S01681591(00)00114-3

Schwaibold, U. and Pillay, N. 2001. Stereotypic behaviour is genetically transmitted in the African striped mouse Rhabdomys pumilio. Applied Animal Behaviour Science 74:273-280. https://doi.org/10.1016/S0168-1591(01)00169-1

Seckl, J. R. 2004. Prenatal glucocorticoids and long-term programming. European Journal of Endocrinology 151(Suppl 3):U49-U62. https://doi.org/10.1530/eje.0.151u049

Siegford, J. M.; Rucker, G. and Zanella, A. J. 2008. Effects of pre-weaning exposure to a maze on stress responses in pigs at weaning and on subsequent performance in spatial and fear-related tests. Applied Animal Behaviour Science 110:189-202. https://doi.org/10.1016/j.applanim.2007.03.022

Souza da Silva, C.; Bolhuis, J. E.; Gerrits, W. J. J.; Kemp, B. and van den Borne, J. J. G. C. 2013. Effects of dietary fibers with different fermentation characteristics on feeding motivation in adult female pigs. Physiology and Behavior 110-111:148-157. https://doi.org/10.1016/j.physbeh.2013.01.006

R. Bras. Zootec., 48:e20180135, 2019 
Terlouw, E. M. C.; Lawrance, A. B.; Ladewig, J.; De Passille, A. M.; Rushen, J. and Schouten, W. G. P. 1991. Relationship between plasma cortisol and stereotypic activities in pigs. Behavioural Processes 25:133-153. https://doi.org/10.1016/0376-6357(91)90016-S

Williams, J. and Randle, H. 2017. Is the expression of stereotypic behavior a performance-limiting factor in animals? Journal of Veterinary Behavior: Clinical Applications and Research 20:1-10. https://doi.org/10.1016/j.jveb.2017.02.006

Zanella, A. J.; Broom, D. M.; Hunter, J. C. and Mendl, M. T. 1996. Brain opioid receptors in relation to stereotypies, inactivity, and housing in sows. Physiology and Behavior 59:769-775.

Zhang, M. Y.; Li, X.; Zhang, X. H.; Liu, H. G.; Li, J. H. and Bao, J. 2017. Effects of confinement duration and parity on stereotypic behavioral and physiological responses of pregnant sows. Physiology and Behavior 179:369-376. https://doi.org/10.1016/0031-9384(95)02118-3

Zonderland, J. J.; de Leeuw, J. A.; Nolten, C. and Spoolder, H. A. M. 2004. Assessing long-term behavioural effects of feeding motivation in group-housed pregnant sows; What, when and how to observe. Applied Animal Behaviour Science 87:15-30. https://doi.org/10.1016/j.applanim.2003.12.009 